\title{
Trichinella thrives in both oxidative and glycolytic human muscle fibres
}

\author{
J OCHOA, AND C PALLIS \\ From the Division of Neurology, Dartmouth Medical School, Hanover, USA and the \\ Department of Neurology, Royal Postgraduate Medical School, London.
}

SUMMARY In a deltoid biopsy from a severe case of human trichinosis the larvae of Trichinella spiralis did not exhibit any predilection for any particular fibre type. Type I and type II fibres were involved with a frequency proportionate to their distribution in the muscle sampled.

No parasitic myopathy has been studied in greater detail than trichinosis. The condition can be reproduced in a wide variety of experimental animals and still has important clinical implications. In view of this it is strange that no attention seems to have been given to the question of whether the larvae of Trichinella spiralis in human skeletal muscle show a predilection foror survive longer in-any particular fibre type. Any such pattern might throw light on the metabolic needs of the larvae, at various stages of their development. The relevant information, if available, is not easily accessible. It could not be found in standard textbooks of clinical parasitology, ${ }^{1-3}$ helminthology, ${ }^{45}$ nematology, ${ }^{6}$ or trichinology $y^{7}$ or, for that matter, in textbooks of clinical myology ${ }^{8}$ or muscle pathology. ${ }^{910}$ This lacuna may be due to the fact that the heyday of trichinosis antedated the widespread use of histochemical techniques in myology.

The diaphragm, intercostal and external ocular muscles are often predominantly involved in trichinosis. The same muscles are also most severely affected in experimental plasmocid poisoning. ${ }^{9}$ The myotoxic effects of plasmocid (8-(3-diethylaminopropylamino) -6-methoxyquinoline dihydrochloride), a protoplasmic poison, are most pronounced in fibres rich in mitochondria. We have recently had the opportunity to make some preliminary observations as to whether the larvae of $T$. spiralis showed any predilection for these type I red fibres.

Address for reprint requests: Dr C Pallis, Royal Postgraduate Medical School, Du Cane Road, London W12 OHS.

Accepted 24 October 1979

\section{Material and methods}

The patient was a woman of 35 years, with severe trichinosis. The clinical details have been published elsewhere. ${ }^{11}$ A biopsy of the left deltoid muscle was carried out during the fourth week of the illness.

Cryostat sections of unfixed muscle, quickly frozen in isopentane cooled in liquid nitrogen, were stained by conventional techniques and reacted for the demonstration of a variety of enzymes. The myofibrillary ATPase reaction ( $\mathrm{pH}$ $9 \cdot 4,4 \cdot 6,4 \cdot 3$ ) was used for muscle fibre typing, as recommended by Dubowitz and Brooke. ${ }^{12}$

\section{Results}

The three distinct muscle fibre types could readily be recognised in the ATPase preparations preincubated at $\mathrm{pH}$ 4.6. Muscle fibres which contained nematode larvae in cross section were usually distended and somewhat modified in their staining properties. The same was true for muscle fibres which contained no larvae but were also distended and showed disrupted internal architecture: these were probably cut very close to the level of an intracellular parasite. The altered staining properties made it impossible to determine whether a given affected muscle fibre was of a subtype $2 \mathrm{~A}$ or $2 \mathrm{~B}$. It was possible, however, confidently to distinguish type 1 from type 2 fibres.

The whole cross section of the biopsy specimen (about 5500 fibres) was scanned in an attempt to determine the histochemical type of affected fibres. Of 100 abnormal muscle fibres encountered 
eight were cut through a parasite. Four of these fibres were of type 1 and three of type 2 . Of the remaining 93 abnormal fibres, 39 were of type 1 , 50 to type 2 , and four of undetermined type. This distribution of affected fibres does not differ significantly from the normal distribution of fibre types in this particular muscle. Figures 1a, b, c, and $d$ illustrate the various types of abnormality encountered.

\section{Discussion}

The pathological effects of the Trichinella larvae on human muscle have been fully described. ${ }^{7}$ They vary from obvious visualisation of the larvae themselves (either before or after encystment) to well organised changes seen in affected fibres (on either side of the parasite) or even, occasionally, in adjacent fibres. Extensive inflammatory or degenerative changes in muscle specimens showing only a few trichinae is well recognised in trichinosis. It was once attributed to the liberation of a hypothetical toxin. Drachman and Tuncbay ${ }^{13}$ showed however-in a meticulous study of serial sections of experimentally parasitised guinea-pig muscle -that the abnormalities were not some form of "remote myopathy" but were confined to regions in the immediate proximity of the larvae themselves.

To these known facts can now be added the observation that, in at least one fully studied patient, the larvae did not show any preference for any particular fibre type.

\section{References}

1 Brumpt E. Precis de Parasitologie. 6th ed. Paris, Masson 1949.

2 Faust EC, Russell PF, Jung RC. Craig and Faust's Clinical Parasitology. 8th ed. Philadelphia, Lea and Febiger. 1970.

3 Adam KMG, Paul J, Zaman V. Medical and Veterinary Protozoology. Edinburgh and London, Churchill Livingstone, 1971.

4 Faust EC, Human helminthology. 3rd ed. Philadelphia, Lea and Febiger. 1949.

5 Muller R. Worms and Disease: a manual of medical helminthology. London, Heinemann. 1975.

6 Levine ND. Nematode parasites of domestic animals and man. Minneapolis, Burgess. 1968.

7 Gould SE. Trichinosis in Man and Animals. Springfield, Thomas. 1970.

8 Walton JN. Disorders of Voluntary Muscle. 3rd ed. Edinburgh and London, Churchill Livingstone. 1974.

9 Adams RD. Diseases of muscle: a study in pathology. New York, Harper and Row. 1975.

10 Hughes JT. Pathology of Muscle. Philadelphia, London, Toronto, Saunders. 1974.

11 Gross B, Ochoa J. Trichinosis: a clinical report and histochemistry of muscle. Muscle and Nerve 1979; 2:394-8.

12 Dubowitz V, Brooke MH. Muscle biopsy: a modern approach. London, Saunders. 1973.

13 Drachman DA, Tuncbay TO. The remote myopathy of trichinosis. Neurology 1965; 15: 1127-35.

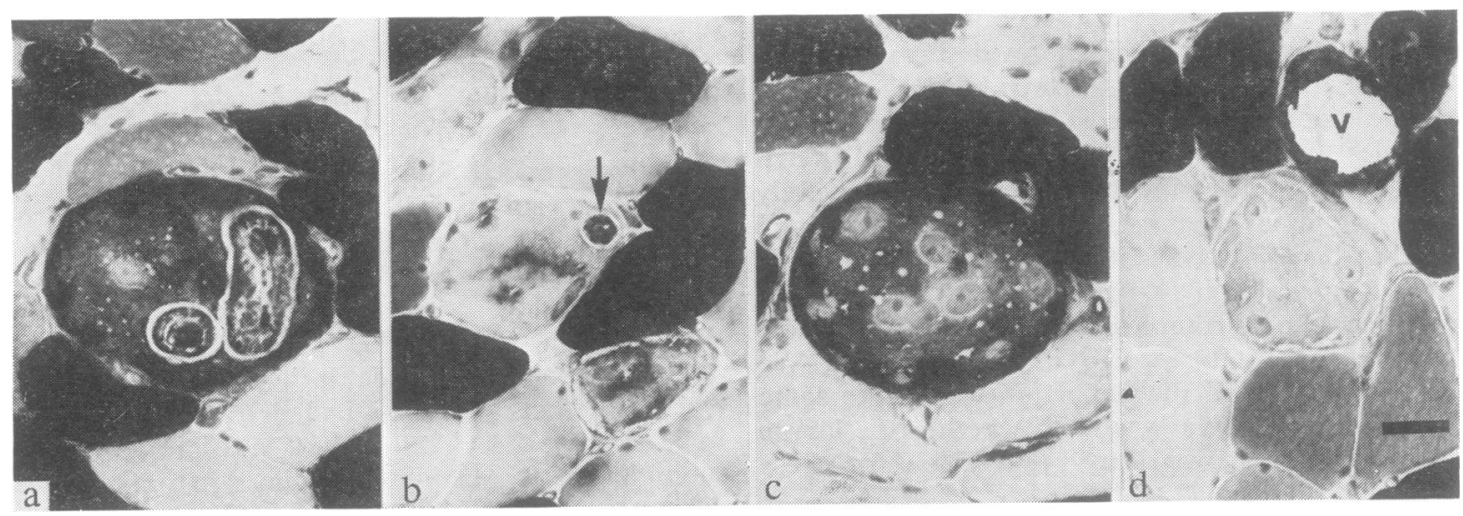

Figure (a) Type 1 muscle fibre harbouring larvae. (b) Type 2 (A?) fibre cut across parasite (arrowed). (c) Distended Type 1 fibre with reactive nucleii, probably cut close to a parasite. (d) Type 2 (A?) fibre showing similar change as the fibre in $c$.

ATPase pH 4.6: Black=Type 1; White $=$ Type 2A; Intermediate $=$ Type 2B; Common Bar $=25 \mu m$; $V=$ blood vessel. 